\title{
The United Front Work Promotes the Integration of the Guangdong-Hong Kong-Macao Greater Bay Area
}

\author{
Chen Xinfei ${ }^{1, a}$ \\ ${ }^{1}$ School of Marxism, Wuhan University of Technology, Wuhan, Hubeis, Chinal \\ achenxinfei2002@163.com
}

\begin{abstract}
The Guangdong-Hong Kong-Macao Greater Bay Area is another important national strategy in the past 40 years of reform and opening-up in Guangdong. Since the reform and opening up, especially after the return of Hong Kong and Macao to the motherland, cooperation between Guangdong, Hong Kong and Macao has been steadily deepened. The economic strength and regional competitiveness of the Greater Bay Area have been significantly enhanced, and the basic conditions for the establishment of an international first-class Bay area and a world-class city cluster have been laid down. In the process of promoting the integration of guangdong-Hong Kong-Macao Greater Bay Area, the united front work has played an active and significant role. Under the new situation, the Guangdong-Hong Kong-Macao Greater Bay Area is facing new problems and opportunities. Therefore, the united Front work should also be combined with the reality, establish the correct guidance under the new situation, give play to the advantages of the united Front thinking, and effectively promote the integration process of the Guangdong-Hong Kong-Macao Greater Bay Area.
\end{abstract}

Keywords: Guangdong-Hong Kong-Macao Greater Bay Area, The united front, "One country, two systems"

\section{统战工作促进粤港澳大湾区一体化研究}

\author{
陈欣菲 1 , a
}

${ }^{1}$ 武汉理工大学马克思主义学院, 武汉, 湖北, 中国

chenxinfei2002@163. com

\section{摘要}

粤港澳大湾区是广东改革开放四十年来又一个重要的国家战略。改革开放以来, 特别是在香港、澳门回归祖国 后, 粤港澳合作不断实化深化, 粤港澳大湾区的经济实力、区域竞争力得到了显著提升, 已具备建立国际一流 湾区与世界级城市群的基础条件。在推进粤港澳大湾区一体化的进程中, 统一战线工作在其中起到了积极显著 的作用。在新形势下, 粤港澳大湾区面临着新的问题与机遇, 为此, 统战工作亦需结合实际, 树立新形势下的 正确导向, 发挥统战思维的优势, 切实推进粤港澳大湾区的一体化进程。

关键词: 粤港澳大湾区，统一战线，一国两制

\section{1. 前言}

珠江三角洲是广东省经济最为发达的地区, 其未 来的发展对全省经济发展具有核心辐射和全面带动 作用。改革开放四十年来, 在推动珠广东省经济发展 的诸多因素中, 港澳因素给广东省带来的优势是其他 地区无法比拟的, 广东省今后的发展, 仍需要持续应 用处于发展和进步中的港澳因素。统一战线是中国共
产党的三大法宝之一，在粤港澳地区的交流合作中， 统一战线工作曾发挥了重要的积极作作用, 在未来推 动粤港澳大湾区一体化的进程中, 统一战线也将持续 发挥其优越性。

\section{2. 粤港澳大湾区发展现状}

推进粤港澳大湾区建设，是习总书记亲自谋划、 
部署、推动的国家战略之一, 具有深远历史意义和重 大现实意义, 是国家发展战略中的重要组成部分, 是 实现粤港澳地区协同发展的重要举措。粤港澳三地在 一体化进程中各具优势, 但仍存在许多问题, 如产业 结构性矛盾、行政体制不同、生态环境问题等，这些 问题都是制约粤港澳大湾区发展的重要因素。在粤港 澳大湾区的统战工作建设中, 要加强党委对统战工作 的领导, 提高自身建设水平, 在粤港澳大湾区建设过 程中，帮助解决实际的困难、提供有力的保障。并将 统战工作的思路和工作重点统一贯彻习近平新时代 中国特色社会主义思想，增强责任担当、更好服务大 局, 加强自身建设、推动粤港澳地区统战工作再上新 台阶。

\section{1. 战略背景}

粤港澳大湾区由深圳、广州、佛山、江门、惠州、 珠海、东莞、中山、肇庆九个泛珠三角地区城市与澳 门、香港两个特别行政区组成, 并在国家发展大局中 占有重要的战略地位。粤港澳大湾区内的珠三角九市 长期以来皆是全国市场化改革的先行者和试验田, 是 市场体系和市场意识较为完备的地区, 香港、澳门是 两个相对成熟的自由经济体。共同的市场经济体系、 共同的市场话语理念、共同依托并交叉融合, 为粤港 澳大湾区的建设提供了经济制度红利。

建设粤港澳大湾区, 是新时代进一步深化全面开放 新格局的新尝试, 也是推动 “一国两制” 事业发展的 新实践。近年来, 粤港澳大湾区在文化、教育、经济 等多个方面进行融合发展, 整合了泛珠三角地区和港 澳地区的各类资源, 发挥了其产业协同优势、地理环 境优势、劳动力资源优势，实现了粤港澳各城市间的 优势互补, 深化了港澳与内地的交流协作。未来, 粤 港澳大湾区将被打造成世界级的经济大平台与发达 市场经济的样本, 开辟成一个可持续性发展的领先区 域、建设成一个开放型的经济结构、打造成一种高效 型的全球资源配置体系。

\section{2. 发展现状}

粤港澳大湾区经过改革开放以来的协同发展, 近 年来产业结构进入转型期, 其中第一第二产业占比不 断下降, 第三产业地位逐渐凸显, 如今已基本形成有 明显特征并较为稳定的产业结构。其中, 广州、佛山、 肇庆三市则以农业及制造业为主; 广州的支柱产业集 中于船舶、汽车制造业及其他重工产业, 佛山则以陶 瓷业及机器制造业为主, 肇庆以农业、旅游业为其支 柱产业, 制造业占比相对较低; 深圳、东莞、惠州的 产业结构呈现了较高同质度, 集中于科技、制药、服 务业等; 中山、珠海、江门三市经济圈产业差异较小, 皆以制造业为主, 其中中山以电器、五金等产业为主, 珠海则主要是电子制造、精密仪器、石油化工为主, 江门以纸质加工产品、交通海洋装备及包装印制业为 主。
第三产业在香港、澳门的产业结构中占据主要地 位, GDP 总值占比高于 $90 \%$ 。其中, 香港的航运产业、 金融贸易占据亚洲领头地位，香港的支柱产业金融服 务业、旅游业、工商支援服务业、贸易与物流业四产 业 GDP 占比六成以上, 为香港经济发展做出巨大贡献。 澳门则以博彩业为基础, 带动资产租赁、餐饮酒店、 金融保险等多元产业的发展，博彩业作为澳门支柱产 业, GDP 总值占比高于 $50 \%$ 。

\section{3. 主要困难}

首先，粤港澳三地拥有不同的社会制度及关税体 系，面临着 “一国、两制、三关税区” 的挑战。在此 基础上，粤港澳地区的法律体系、经济制度有较大的 不同, 使得部分资源无法灵活的流动, 部分领域甚至 出现同质竞争，资源错配的问题，这使得湾区内各城 市缺乏对粤港澳大湾区一体化观念的价值认同。粤港 澳大湾区的协同性有待加强。

其次，粤港澳地区的创新驱动力处于劣势。粤港 澳大湾区内高等院校众多, 但缺乏世界先进研究机构, 与此同时, 湾区内各学校间资源整合力度较差, 难以 进行分工协作。且技术的联合研发环境仍不成熟, 使 湾区内的人才、技术流动受阻, 从而无法形成创新合 力, 进行原始创新的能力不足。

再次, 大湾区内部的发展差异较大, 其中, 香港 经济发展缺乏实业支撑, 澳门以博彩旅游业为主, 经 济结构相对单一, 且港澳土地资源有限, 区域发展空 间受到较大制约，而珠三角地区随着内部市场相对饱 和, 整体产业结构面临转型升级的大背景下, 部分经 营传统行业的中小企业也面临着发展困境。

同时，由于历史遗留因素，粤港澳三地缺乏共同 的文化认同感，难以形成精神层面的区域认同，使得 大湾区的发展合力难以聚集。如今, 珠三角九市面临 人口红利逐步消退, 生态压力日益增大等问题, 处于 结构转型的关键时期, 粤港澳大湾区发展所面临的困 境, 既是挑战, 也是机遇。

\section{3. 统战工作促进粤港澳大湾区一体化的优势}

新时期统战工作在合理继承的基础上发展了马 克思和历任领导人的统战思想, 巩固了中国共产党的 执政水平建设,维护和推进了国家的和平统一。党的 十九大报告指出, “统一战线是党的事业取得胜利的 重要法宝, 必须长期坚持” 习总书记关于新时代中国 统一战线发展的重要论述是引领新时代粤港澳地区 融合发展的重要指导思想, 也是习近平新时代中国特 色社会主义思想的现实运用。促进粤港澳大湾区更好 地凝聚共识、凝聚智慧、凝聚人心、凝聚力量。

\section{1. 凝聚一体化共识的优势}

由于历史遗留因素，港澳在较长的一段时间内与 祖国分离, 且在两种不同的发展模式下, 部分港澳地 
区人民对祖国缺乏全面的认识和了解。一方面，港澳 文化根植于传统中华文化，但另一方面，港澳文化 吸收并融合了大量以英国、葡萄牙所代表的西方国家 的政治倾向、社会氛围及文化思想，促成港澳地区在 思维方式、审美情趣、思想认知等方面与广府文化的 内涵和风格上存在差异, 并且在较长的一段时间内保 持着自我独立的发展轨迹。导致在粤港澳城市群建设 初期, 港澳地区的部分民众对粤港澳大湾区一体化的 观念认同及价值认同感到迷茫, 因此也导致粤港澳三 地的发展共识有所缺乏。

粤港澳统战工作是新时期推进建设粤港澳大湾 区城市群的重要举措。粤港澳大湾区共同的根脉和纽 带是同根同源的岭南文化、广府文化, 是中华优秀传 统文化。统战工作能够不断地壮大具有广泛包容性的 爱国爱澳、爱国爱港统一战线, 推进建设以爱国者作 为主体的 “澳人治澳”、“港人治港” ，打造粤港澳 三地的爱国统一战线, 开展大湾区交流合作, 进一步 夯实了港澳地区与珠三角九市团结友好的建设根基, 唤醒了粤港澳三地对其本根同源的认知, 凝聚促进粤 港澳大湾区一体化的发展共识, 培养对粤港澳的观念 认同及价值认同，从而在精神上形成发展合力，共同 促进湾区建设。

\section{2. 凝聚一体化智慧的优势}

整合粤港澳人才、创新合作形式、凝聚一体化智 慧、激发一体化活力。在 2019 年 2 月印发实施的《粤 港澳大湾区发展规划纲要》中提出, 在大湾区为青年 人提供创业、就业、实习和志愿工作等机会, 推动青 年人交往交流、交心交融, 支持港澳青年融入国家、 参与国家建设。

粤港澳大湾区的广州、深圳和香港地区学校众多, 人才云集。但湾区各城市间的发展水平存在一定差距, 导致人才资源分配不均匀, 对湾区协同发展产生消极 影响。统战工作能够促成整合湾区资源这一目标的实 现, 推动缩小湾区各城市间的基础设施差距, 加强人 才集聚效应, 帮助粤港澳大湾区的中小型城市吸引高 层次创新人才, 并统筹规划, 根据大湾区内不同城市 所需的高层次创新人才种类的差异，对其制定梯度 化人才引入的激励政策, 以达到优化粤港澳大湾区各 城市内的高层次创新人才配置, 凝聚一体化智慧, 促 进粤港澳协同发展。

\section{3. 凝聚一体化人心的优势}

习近平指出：“人心向背、力量对比是决定党和 人民事业成败的关键, 是最大的政治。统战工作的本 质要求, 是大团结大联合, 解决的就是人心和力量问 题。”习近平总书记多次讲过, 政权在手, 不一定 人心在握。在中央统战工作会议上, 他又指出, 世界 上什么事情最难做? 应该就是争取人心了。有效凝聚 粤港澳人心、增进三地共识, 巩固壮大港澳台爱国力 量, 是决定粤港澳一体化工作成败的关键。粤港澳地
区的统战工作在凝聚人心方面发挥了重大作用。近年 来, 我国香港、澳门发生的少数政治事件能够充分证 明: 仅仅依靠经济利益纽带, 是不能带来人心回归的。 人民群众是物质财富和精神财富的创造者, 是历史的 创造者, 因此, 在粤港澳大湾区的统战工作中的一个 重要方面就是通过各项工作以凝聚人心、争取人心, 以夯实粤港澳三地团结和谐发展, 艻实粤港澳人民群 众共同推进粤港澳大湾区长治久安和持续发展的情 感基础、群众基础、民心基础。

凝聚人心工作始终贯穿于统战思想指导下的粤 港澳建设、发展和稳定的全过程。在建设粤港澳大湾 区的过程中, 持续开展大联谊大交友、大走访大谈心、 大学习大宣传活动, 使粤港澳三地市民把思想与行动 都统一于党中央的决策部署, 积极投身到粤港澳大湾 区建设的主战场。凝聚人心工作亦推动了粤港澳地区 民营经济发展，加强了政企沟通、促进了粤港澳三地 间企业家的交流，推动了民营企业解决粤港澳企业协 同发展中难点、堵点、痛点问题的进程, 引导港澳企 业家树立良好的家国情怀，为粤港澳地区的发展做出 贡献。凝聚人心工作推动粤港澳城市群拧成一股绳, 在推动湾区一体化发展的同时也巩固了爱国主义统 一战线, 促进养成港澳同胞在守住安全发展底线上的 担当精神, 推动防范与化境外渗透风险, 为粤港澳地 区全方位、多层次、宽领域的开放提供坚强保障。

\section{4. 凝聚一体化力量的优势}

在粤港澳大湾区的建设过程中, 党委统战部认真 研究在新形势下的粤港澳统战工作的新变化和特点, 牢牢的把握住大联合大团结的主题, 贯彻执行拓宽新 领域、搭建新平台、体现新作为的方针政策, 推动粤 港澳凝聚力、一体化程度和影响力的提升。

统战工作推动构建了湾区内的协同机制构建，协 调了龙头角力与城市间的关系, 从而为大湾区的产业 布局与发展问题指明了道路。相比于世界的其他湾区, 粤港澳湾区内的体制机制较为复杂, 统战工作凝聚力 量, 凝聚智慧, 凝聚人心, 提高了粤港澳城市群的资 源整合质量和融合发展质量, 使湾区内各城市逐渐相 互渗透, 相互融合, 推动各城市间协调发展, 聚集整 合粤港澳大湾区的资源优势, 从而凝聚粤港澳力量, 形成发展合力, 加速湾区的一体化进程。使粤港澳大 湾区规划赢得了海外地区、泛珠三角城市和社会各界 的广泛认同, 并为新时代改革开放的新模式和经济建 设新思路提供了良好的建设模板和先进经验。

\section{4. 统战工作推进粤港澳大湾区一体化的优势}

粤港澳一体化是历史发展的趋势, 粤港澳合作是 广东经济发展硕果累累的一个重要因素。在新时代粤 港澳大湾区的建设中, 应发挥统一战线工作积极显著 的作用。在统战思想的指引下, 进一步发挥统战工作 凝聚共识、凝聚人心、凝聚智慧、凝聚力量的优势, 建立粤港澳间的爱国精神纽带，搭建、完善粤港澳交 
流合作和服务平台，推进粤港澳人才高地建设，从而 推进粤港澳大湾区的一体化进程。

\section{1. 建立爱国精神纽带}

统战工作要在粤港澳大湾区中探索出将统战与 社会阶层工作、社会文化相结合的有效途径，要做好 港澳工商界中坚力量的工作，以港澳爱国传统与同根 同源的广府文化为基石，建立爱国精神纽带。

早在上个世纪, 港澳地区就涌现了一批爱国企业 家, 如霍英东、何鸿䅇等, 他们积极参与祖国内地的 经济、文化建设和慈善事业, 为香港、澳门的发展做 出了突出的贡献。因此, 要建立爱国精神纽带, 就要 发掘新时代粤港澳地区各领域内爱国、爱党的人才, 建立一支拥护党的领导, 拥护改革开放, 坚持走中国 特色社会主义道路的粤港澳人才队伍, 从而建立并巩 固粤港澳三地间的爱国精神纽带, 使之成为粤港澳大 湾区一体化的要力。

在历史进程中，粤港澳大湾区在政治、经济、文 化方面长期处于整体状态。由于粤港澳三地同属于广 府文化圈, 所以在自然地理、乡俗人员、语言习惯等 方面都表现出较为统一的文化特性。粤港澳大湾区的 文化基础融合了传统的广府文化、客家文化、岭南文 化等地域性传文化, 并在发展过程中吸收了华侨文化 等文化元素, 形成了如今和而不同的粤港澳文化, 粤 港澳文化的同根同源为三地的交流奠定了深厚的基 础, 而三地的文化差异亦为粤港澳文化交流提供了契 机。统战工作应把握这一文化特点, 以文化为根源建 立爱国精神纽带。

\section{2. 搭建交流平台}

统战优势的发挥除制定方针外, 还应搭建科学有 效的平台, 使方针得以落实。搭建交流平台有利于发 挥统一战线代表性广泛的优势, 破除交流合作中的体 制机制障碍, 减小信息差成本, 有利于使各城市进行 深度交流，以协调好湾区内的城市定位。

粤港澳三地有着具备自身特色的定位和发展方 向, 在推进粤港澳一体化建设的过程中, 应该结合城 市定位, 构建功能多样、分布广泛的珠三角内不同城 市不同层面的合作交流平台, 按照创新活力、宜居生 活、教育医疗、司法行政、产业合作等内容, 探索建 立不同类型的粤港澳大湾区合作交流平台, 从而为粤 港澳大湾区经济、政治、文化、生态和社会的全方面 一体化发展积累不同类型、不同层面的经验。

搭建交流平台是实现湾区各城市间协调发展, 并 在经济、政治、文化产业等层面展开深度合作的重要 条件, 如此才能使各城市发挥自身优势、弥补自身劣 势, 进而在协作共赢、优势互补的合作格局下, 为粤 港澳大湾区的发展指明新的方向。

\section{3. 推进人才高地建设}

统一战线具有代表广泛、智力密集的优势, 但粤 港澳缺乏高质量人才, 给湾区的创新性发展带来阻碍。 以是否接受过高等教育为划分人才的标准, 根据 2015 年全国 $1 \%$ 人口抽样调查数据, 估算出粤港澳大湾区接 受高等教育人才达 1187.81 万, 占 6797.48 万常住人 口的 $17.37 \%$ 。根据中共中央组织部关于人才资源总量 的统计口径, 人才资源总量包括企业经营管理人才、 党政人才、高技能人才、专业技术人才、社会工作人 才和农村实用人才, 2016 年, 粤港澳大湾区人才规模 为 1431.16 万人, 占总人口数的 $21.05 \%$ 。此规模与世 界其他湾区相比显著偏低。如就高等教育人口数量单 指标计算，日本与美国的高等教育人口比重均在 $40 \%$ 及以上。

粤港澳大湾区将打造 “全球创新发展高地” 作 为战略定位和核心竞争力的前提是打造 “人才高 地” , 在创新性上获取突破、有所建树的关键因素便 是人才建设, 人才要素是统合资本、产业、技术等要 素的桥梁。要促进粤港澳交流合作, 应当进一步发挥 统战优势, 发现人才、发展人才, 进行积极的投入和 拓展, 借助他们的创新力量和创新思维, 积极促成大 湾区的互通协作, 打破发展瓶颈, 推动湾区传统产业 的转型升级和创新性发展, 夯实粤港澳大湾区的核心 竞争力。

\section{5. 总结}

如今粤港澳大湾区正处于发展阶段, 粤港澳建设 及统一战线工作亦应在党的指导下得到进一步的发 展, 注重自身的改革创新, 攻坚克难。港澳作为统一 战线的重要组成部分, 与祖国安定、民族复兴休戚相 关。在新时代背景中, 更应充分认识粤港澳统战的重 要意义。合实际, 树立新形势下的正确导向, 发挥统 战思维的优势, 切实推进粤港澳大湾区的一体化进程。

\section{REFERENCES}

[1] Xi Jinping. Securing a Decisive Victory in Building a Moderately Prosperous Society in All Respects and Striving for the Great Victory of Socialism with Chinese Characteristics for a New Era -- Report delivered at the 19th National Congress of the Communist Party of China (October 18, 2017)[N]. People's Daily, 2017-1028(1).

[2] Written by The State Council, CPC Central Committee. Outline of the Guangdong-Hong KongMacao Greater Bay Area Development Plan. Beijing: People's Publishing House, 2019.

[3] Central Socialist Institute of Theoretical Learning Center group. Draw the largest concentric circles Xi Jinping central United Front work Conference important speech spirit study lecture. Beijing: Party 
School Of the CPC Central Committee Press, 2015.06

[4] National Bureau of Statistics, Population and Employment Statistics.2015 Sample survey of 1\% of the population. Beijing: China Statistics
Press,2016.01.

[5] Chen Shaofang. Giving full play to the Advantages of United Front to Promote The Cooperation between Guangdong, Hong Kong and Macao [J]. Journal of Guangdong Socialist Institute,2010,(1) 